\title{
Increasing the Yield of Biogas and Electricity during Manure Fermentation Cattle by Optimally Adding Lime to Extruded Straw
}

\author{
${ }^{1}$ Polishchuk V.M., ${ }^{1}$ Shvorov S.A., ${ }^{2}$ Flonts I.V., ${ }^{1}$ Davidenko T.S., ${ }^{1}$ Dvornyk Ye.O. \\ ${ }^{1}$ National University of Life and Environmental Sciences of Ukraine, Kyiv, Ukraine \\ ${ }^{2}$ Separate subdivision "Berezhany Agrotechnical Institute" National University of Life and \\ Environmental Sciences of Ukraine, Berezhany, Ukraine
}

\begin{abstract}
The aim of the work is to increase the yield of biogas and the generation of electricity in biogas plants through the combined fermentation of cattle manure with extruded wheat straw and slaked lime. To achieve this goal, the following tasks were solved: the biogas yield from cattle manure with pellets of extruded wheat straw was determined without the use of slaked lime; when fermenting manure and pellets of extruded straw with different amounts of lime before extrusion, during extrusion and after extrusion with periodic loading of the bioreactor. The biogas volume was measured using the Krivoruchko method. To carry out the experiment, we used plastic bags (fermenters), a device for sealing the bags, a pH meter, and a calibrated cylinder. A seed was added to the calculated amount of biomass at the rate of 1 part of the sample to 4 parts of the seed, air was displaced from the fermenter and the hole was hermetically sealed. After that, the bag was placed in a thermostat at $37.5^{\circ} \mathrm{C}$ for 35 days. The volume of the bags was measured every seven days. On the basis of the experimental studies, the dependence of the biogas yield depending on the concentration, as well as the method of adding a solution of slaked lime in straw (before, during, after extrusion) was determined. The most significant research result is that the optimal ratio of straw extruded together with lime as a cosubstrate will increase the output of biogas and electricity by more than $60 \%$.
\end{abstract}

Keywords: biogas, substrate, cattle manure, winemaking waste, dry organic matter, digester, biogas plant, methane fermentation.

DOI: https://doi.org/10.52254/1857-0070.2021.1-49.02

UDC: 662.763.3.2

Creșterea producerii de biogaz și electricitate în timpul fermentării gunoiului de bovine prin adăugarea de paie extrudată și var

${ }^{1}$ Polisciuk V. M., ${ }^{1}$ Șvorov S. A., Flionț I.V., ${ }^{1}$ Davidenko T. S., ${ }^{1}$ Dvornîk E.O.

${ }^{1}$ Universitatea Națională de Bioresurse și Managementului Naturii din Ucraina, Kiev, Ucraina

${ }^{2}$ Subdiviziune separată „Institutul Agrotehnic Berezhany” al Universității Naţionale de Bioresurse şi

Managementul Naturii din Ucraina, Berezhany, Ucraina

Rezumat. Scopul lucrării este de a crește producere de biogaz și generarea de energie electrică în instalațiile de biogaz prin fermentarea în comun a gunoiului de grajd de bovine cu paie de grâu extrudată și var stins. Pentru a atinge acest obiectiv, s-au rezolvat următoarele sarcini: s-a determinat producția de biogaz din gunoiul de grajd de bovine cu pelete de paie, de grâu extrudată fără utilizarea varului stins; la fermentarea gunoiului de grajd și a peletelor de paie extrudate cu cantități diferite de var înainte de extrudare, în timpul extrudării și după extrudare cu încărcare periodică a bioreactorului. Volumul de biogaz a fost măsurat folosind metoda Krivoruciko. Pe baza studiilor experimentale, dependența producției de biogaz de pretratarea paiului cu o soluție de var stins de diferite concentrații, precum și metoda de adăugare a unei soluții de var stins în paie (înainte, în timpul, după extrudare) a fost determinată. Noutatea subiectului ales constă în utilizarea tratamentului chimic al paiului în combinație cu extrudarea. În timpul extrudării, se efectuează prelucrări termochimice suplimentare. Avantajul utilizării peletelor de paie de grâu extrudat este că astfel de materii prime sunt mai bine transportate sau depozitate într-un depozit. Peleții sunt recomandabili pentru funcționarea continuă a instalațiilor de biogaz, deoarece deșeurile agricole sunt sezoniere. Semnificația rezultatelor cercetării constă în faptul că utilizarea paiului extrudat împreună cu varul ca co-substrat va crește producția de biogaz și electricitate cu mai mult de $60 \%$.

Cuvinte-cheie: biogas, substrat, cattle manure, lime, dry organic matter, extruded straw, biogas plant, methane fermentation.

(С Полищук В. М., Шворов С. А.,Фльонц И.

В., Давиденко Т. С., Дворник Е. А., 2021 


\section{Повышение выхода биогаза и электроэнергии при сбраживании навоза крупного рогатого скота путем оптимального добавления извести к экструдированной соломе \\ ${ }^{1}$ Полищук В. М., ${ }^{1}$ Шворов С. А., ${ }^{2}$ Фльонц И.В., ${ }^{1}$ Давиденко Т. С., ${ }^{2}$ Дворнык Е.А. \\ ${ }^{1}$ Национальный университет биоресурсов и природопользования Украины, Киев, Украина ${ }^{2}$ Обособленное подразделение "Бережанский агротехнический институт" Национального университета биоресурсов и природопользования Украины, г. Бережаны, Украина}

Аннотация. Целью работы является повышение выхода биогаза и выработки электроэнергии на биогазовых установках за счет совместного сбраживания навоза крупного рогатого скота с экструдированной соломой пшеницы и гашеной известью. Для достижения поставленной цели решались следующие задачи: определялся выход биогаза из навоза крупного рогатого скота с пеллетами экструдированной соломы пшеницы без применения гашенной извести; при сбраживании навоза и пеллет экструдированной соломы с различным количеством извести до экструзии, во время экструзии и после экструзии. На основе использования метода динамического программирования определялся оптимальный вариант загрузочного сырья. Измерение объема биогаза проводилось по методу Криворучко. Для проведения опыта использовались полиэтиленовые пакеты (ферментеры), устройство для запайки пакетов, $\mathrm{pH}-\mathrm{метр,} \mathrm{калиброванный} \mathrm{цилиндр.} \mathrm{К} \mathrm{рассчитанному} \mathrm{количеству} \mathrm{биомассы}$ добавлялась затравка из расчета 1 часть пробы до 4 частей затравки, вытеснялся воздух из ферментера и герметично запаивалось отверстие. После этого пакет помещался в термостат при температуре $37,5^{\circ} \mathrm{C}$ на 35 суток. Измерение объема пакетов проводилось через каждые семь дней. На основе проведенных исследований определен оптимальный вариант предварительной обработки соломы раствором гашенной извести разной концентрации (до, во время, после экструзии). Новизна выбранной темы состоит в оптимизации химической обработки соломы в сочетании с экструзией. При экструзии проходит дополнительная термохимическая обработка. Преимущество использования пеллет экструдированной соломы пшеницы заключается в том, что такое сырье лучше транспортируется или хранится на складе. Пеллеты целесообразны для непрерывной работы биогазовых установок, поскольку отходы сельскохозяйственного производства имеют сезонный характер. Наиболее существенным результатом исследований является то, что оптимальное соотношение экструдированной совместно с известью соломы в качестве косубстрата позволит увеличить выход биогаза и электроэнергии более чем на $60 \%$.

Ключевые слова: биогаз, субсстрат, навоз КРС, известь, сухое органическое вещество, экструдированная солома, завод по производству биогаза, метановая ферментация.

\section{LIST OF ABBREVIATIONS}

КРС - крупный рогатый скот; СВ - сухое вещество; $\mathrm{COB}$ - сухое органическое вещество; VS - летучее твердое вещество.

\section{Введение}

Мировая ситуация с энергоносителями характеризуется, с одной стороны, постоянным ростом цен на ископаемое топливо, особенно нефть, а с другой уменьшением ее разведанных запасов. По некоторым прогнозам, запасы нефти практически иссякнут к 2050 г. В то же время общее использование энергии человечеством постоянно растет.

Недостаток ископаемых энергетических ресурсов в мире приводит к расширению использования альтернативных источников энергии. Заменить ископаемые источники энергии сможет биомасса - экологически чистое возобновляемое сырье, ежегодные ресурсы которой на планете значительно превышают энергетические потребности человечества. Поэтому производство энергоносителей из биомассы становится одним из важнейших приоритетов при решении энергетических, a также экологических проблем и имеет глобальную перспективу для дальнейшего развития. Как известно, навоз КРС часто используется для получения биогаза, из которого вырабатывается электрическая и тепловая энергия. Однако, вследствие наличия в навозе большого количества сырой клетчатки, выход биогаза при его сбраживании с помощью биогазовых установок относительно низкий. Поэтому актуальной задачей является повышение выхода биогаза из навоза КРС за счет использования различных стимулирующих брожение добавок. Если же такая стимулирующая добавка является отходом производства, при этом решается задача ее утилизации, тем самым улучшается экологическая ситуация в регионе.

\section{І. ПОСТАНОВКА ЗАДАЧИ}

С целью повышения выхода биогаза и выработки энергии на данное время широко практикуется совместное сбраживание навоза 
КРС с силосом кукурузы. Вместе с тем, данное сырье можно использовать в качестве корма для животных и продуктов питания для человека. Среди альтернативных источников энергии все большее значение приобретает получение биогаза из отходов, к которым относятся навоз, солома, стебли и тому подобное. В Украине избыток соломы и стеблей всех культур составляет примерно 20 млн т. Поэтому для повышения выхода биогаза из навоза КРС целесообразно использовать более дешевое сырье, стимулирующее выход биогаза - отходы при сборе пшеницы (солому), которые необходимо утилизировать с минимальными затратами, улучшая при этом экологию.

Солома трудно поддается анаэробному брожению, поскольку содержит прочный лигниноцеллюлозный комплекс. Существуют различные способы обработки лигниноцеллюлозных материалов, которые делают их доступнейшими для анаэробных микроорганизмов. Одним из них является предварительная химическая обработка соломы гашеной известью. Однако на данное время недостаточно изучены возможности использования гашеной извести в сочетании с экструзией соломы для интенсификации процесса брожения.

Целью работы является повышение выхода биогаза и выработки электроэнергии на биогазовых установках за счет совместного сбраживания навоза крупного рогатого скота с экструдированной соломой пшеницы и гашеной известью. Для достижения поставленной цели решались следующие задачи: определялся выход биогаза из навоза крупного рогатого скота с пеллетами экструдированной соломы пшеницы без применения гашенной извести; при сбраживании навоза и пеллет экструдированной соломы с различным количеством извести до экструзии, во время экструзии и после экструзии при периодической загрузке биореактора.

\section{II. АНАЛИЗ ПОСЛЕДНИХ ИССЛЕДОВАНИЙ}

В работе [1] исследовалась щелочная делигнификация соломы с помощью гидроксида натрия $(\mathrm{NaOH})$. Оптимальные условия делигненизации и ферментативного гидролиза были определены как $0,5 \% \mathrm{NaOH}$ при $50^{\circ} \mathrm{C}$ в течении 3-5 час. та 15 мкл $\mathrm{L}$ Cellic/г предварительно обработанной соломы при $50^{\circ} \mathrm{C}$. В работе [2] эффективными способами делигнификации соломы является обработка ее перекисью водорода $10 \%$ и $\mathrm{NaOH} 2 \%$ с эффективностью соответственно $89,60 \%$ и $84,86 \%$. В работе [3] исследовали 48-часовую предварительную обработку пшеничной соломы $\mathrm{Ca}(\mathrm{OH})_{2} \quad 7,4 \%$. Добавление в сочетании с ее измельчением до размера $1,25,2,3$ и 10 мм при трех периодах сбраживания $(5,15$ и 30 суток). Измельчения соломы до размера 3,2 и 1,25 мм давали выход биометана после 30 суток брожения между 301 и 335 мл $\mathrm{CH}_{4} /$ V VS против контрольных 48 мл $\mathrm{CH}_{4} /$ ч.

В работе [4] проводилась обработка соломы проса щелочью $\left(\mathrm{Ca}(\mathrm{OH})_{2}, \mathrm{NaOH}\right.$ и $\mathrm{KOH})$ с концентрацией $1,2,3$ та $4 \%$ щелочи на 100 г соломы при температуре $52^{\circ} \mathrm{C}$. Результаты показали, что наибольший выход биометана (140 л/кг) был получен при обработке соломы $2 \%$ гидроксидом калия $(\mathrm{KOH})$, по сравнению с выходом биометана 85 л/кг с необработанной соломы. Несмотря на тот факт, что более высокая доза щелочи вызвала усиленное разрушение лигнина, наблюдалось снижение выхода метана по сравнению с более низким дозированием щелочи. В работе [5] сказано, что при обработке кукурузной соломы $\mathrm{KOH} \mathrm{8 \%} \mathrm{было}$ получено максимальный выход метана, который был на $31,9 \%$ больше, чем без обработки. При этом более $76 \%$ калия содержалось в субстрате в водорастворимом виде. А в работе [6] отмечается, что при обработке пшеничной соломы $\mathrm{KOH} 6 \%$, выход биогаза и биометана был на $55 \%$ и на $52 \%$ выше, чем без обработки. В работе [7] показано, что производительность метантенка была повышена за счет ультразвуковой обработки пшеничной соломы в течение 36 ч. после ее предварительной обработки гидроксидом калия. Наблюдалось значительное повышение скорости биодеструкции, производства биогаза и биометана. Выход биогаза составил 570+/-9 мл/г VS, биометана - 306+/-12 мл/г VS. Скорость биодеградации повышалась на $76 \%$.

Для уменьшения времени метанового сбраживания и увеличение выхода биометана, как указано в [8], солома пшеницы обрабатывалась гидроксидом калия в концентрации $1 \%, 3 \%, 6 \%$ и $9 \%$ при температуре окружающей среды. При предварительной обработке $6 \% \quad \mathrm{KOH}$ наблюдался лучший выход биогаза и 
биометана в размере 258 мл/г VS были увеличены на $45 \%$ и $41 \%$ соответственно по сравнению с необработанной соломой пшеницы.

В работе [9] описано, что рисовую солому предварительно обрабатывали щелочью $\mathrm{Ca}(\mathrm{OH})_{2}$ при трех температурных режимов $\left(5^{\circ} \mathrm{C}, 20^{\circ} \mathrm{C}\right.$ та $\left.35^{\circ} \mathrm{C}\right)$ и разного времени обработки (1, 2, 3 и 4 суток). Результаты показали, что оптимальное условие предварительной обработки для рисовой соломы составляет $35^{\circ} \mathrm{C}$ в течение 2 суток. В этом случае максимальный выход биометана достиг 308 мл/г VS, что на 77,4\% выше, чем при контрольном опыте.

В работе [10] указано, что после предварительной обработки кукурузной соломы $1,5 \% \mathrm{Ca}(\mathrm{OH})_{2}$ при температуре $120^{\circ} \mathrm{C}$ последующее ее совместное сбраживания с навозом КРС давало выход биометана 0,41 $\mathrm{M}^{3} / \mathrm{K} \Gamma \mathrm{VS}$.

В работе [11] приведены результаты исследований влияния гидротермальной и щелочной обработки соломы на ее метановое сбраживание. Результаты показали, что накопленный выход биогаза был самым высоким для после щелочной обработки $2 \%$ $\mathrm{Ca}(\mathrm{OH})_{2}(411,1$ мл/г VS), что на $24,04 \%$ выше по сравнению с контрольным опытом.

В работе [12] утверждается, что выход биогаза колебался между 14 і 42\% для соломы пшеницы и 9-33\% для соломы проса после их обработки гашеной известью $\mathrm{Ca}(\mathrm{OH})_{2}$ в диапазоне загрузки $0-60 \% \mathrm{Ca}(\mathrm{OH})_{2}$.

В работе [13] утверждается, что для увеличения выхода биогаза предварительная обработка пшеничной соломы КОН дает лучшие эффекты, чем $\mathrm{Ca}(\mathrm{OH})_{2}$. Однако обработка $2 \% \mathrm{KOH}$ в сочетании з $1 \% \mathrm{Ca}(\mathrm{OH})_{2}$ дает аналогичный эффекты, как с $3 \% \mathrm{KOH}$, получая накопительный выход биометана 239,8 мл/Г и улучшено биоразложение 3 $56,37 \%$ до $66,10 \%$. Уровень выхода биометана позволяет предположить, что $2 \%$ $\mathrm{KOH}$ в сочетании с $1 \% \mathrm{Ca}(\mathrm{OH})_{2}$ является идеальным условием щелочной обработки пшеничной соломы для осуществления ее метанового сбраживания.

В работе [14] приведено сравнение эффективности предварительной обработки рисовой соломы перекисью водорода $\left(\mathrm{H}_{2} \mathrm{O}_{2}\right)$ та гидроксидом кальция $\left(\mathrm{Ca}(\mathrm{OH})_{2}\right)$ в мезофильных условиях при температуре $37+/$ $1^{\circ} \mathrm{C}$. Максимальный выход биометана наблюдался при предварительной обработке
$\mathrm{H}_{2} \mathrm{O}_{2}$ концентрацией $0,3 \%$ и $\mathrm{Ca}(\mathrm{OH})_{2}$ концентрацией $\left(331,6\right.$ мл $\mathrm{CH}_{4} / \Gamma$ VS та 346,7 мл $\mathrm{CH}_{4} / \Gamma$ VS соответственно).

Результаты исследований, приведенных в [15], показали, что биохимическая обработка рисовой соломы негашеной известью $\mathrm{CaO}$ вместе с жидкой фракцией дигестату достигала лучшего эффекта среди различных условий предварительной обработки (раствором аммиака, жидкой фракцией дигестату, раствором аммиака вместе с негашеной известью). Выход биометана при этом составил 274,65 мл/г VS, что на $57,56 \%$ больше, чем в контрольном опыте.

В работе [16] приведены результаты исследования щелочной обработки рисовой соломы $\mathrm{NaOH}$ в концентрации $3 \%, 5 \%$ i $7 \%$ при температуре $100^{\circ} \mathrm{C}, 120^{\circ} \mathrm{C}$ i $140^{\circ} \mathrm{C}$. Обработка осуществлялась в автоклаве при соотношении воды и соломы 8:1 в течение 2 ч. Было установлено, что наивысшая органическая деградация рисовой соломы происходит при более высокой температуре и концентрации $\mathrm{NaOH}$.

В работе [17] приведены результаты исследований предварительной обработки рисовой соломы добавлением от $0 \%$ до $7 \%$ $\mathrm{NaOH}$ при температурах $100-200^{\circ} \mathrm{C}$. Установлено, что содержание фракций лигнина и гемицеллюлозы уменьшается с увеличением температуры и содержания $\mathrm{NaOH}$.

В работе [18] утверждается, что обработка соломы каустической содой $\mathrm{NaOH}$ более эффективна по сравнению с ее обработкой аммиаком $\mathrm{NH}_{3}$, горячей водой и паром и измельчением.

Результаты, приведенные в работе [19], показали, что в увеличении кумулятивного выхода биогаза (на 21,4\%) щелочная обработка $\mathrm{NaOH}$ была более эффективной, чем добавление микроэлементов $\mathrm{Co}, \mathrm{Ni}$ и $\mathrm{Se}$.

После предварительной обработки пшеничной соломы $\mathrm{NaOH}$, как показано в [20], выход биогаза увеличился на 23\%, тогда как после обработки ее гидролитическими ферментами - на $14 \%$.

После предварительной обработки 12 г $\mathrm{NaOH} / 100$ г измельченной до размера 2 мм соломы сахарного тростника, как отмечается в [21], выход биометана вырос на $11,9 \%$ (3 260 до 291 мл $\mathrm{CH}_{4} / \mathrm{g}$ VS).

Самый высокий выход биогаза с измельченной рисовой соломы (1 мм), предварительно обработанной $1 \%$ гидроксидом натрия $\mathrm{NaOH}$ при температуре окружающей 
среды в течение 180 мин., в работе [22] составил 514 л/кг VS-сутки (при 59\% $\mathrm{CH}_{4}$ ).

В работе [23] описаны результаты исследований предварительной обработки пшеничной соломы $\mathrm{NaOH}$ концентрациями $1 \%, 2 \%, 4 \%$ та $6 \%$. Установлено, что, используя $4 \% \mathrm{NaOH}$ для предварительной обработки, было получено на $40,0 \%$ больше общего производства биогаза и на $48,1 \%$ биометана, чем с необработанной соломой.

Как описано в работе [24], солому предварительно обрабатывали в течение 1-5 ч. с помощью 0,5 і 1 моль/л карбоната натрия $\left(\mathrm{Na}_{2} \mathrm{CO}_{3}\right)$ при $120^{\circ} \mathrm{C}, \quad 150^{\circ} \mathrm{C}$ та $180^{\circ} \mathrm{C}$, в результате чего получили жидкую фракцию, содержащую гемицелюлозни сахара и твердую фракцию, преимущественно содержит целлюлозу. Самый высокий выход биометана с твердой фракции составил 139,6 мл/г VS после предварительной обработки при $120^{\circ} \mathrm{C} 0,5$ моль/л $\mathrm{Na}_{2} \mathrm{CO}_{3}$ в течение 1 ч., тогда как с необработанной соломы было только 92,1 мл/г VS. С другой стороны, из жидкой фракции после предварительной обработки 0,5 моль/л $\mathrm{Na}_{2} \mathrm{CO}_{3}$ при $180^{\circ} \mathrm{C}$ в течение 2 ч. получали максимум 88,2 мл/г VS метана.

Улучшение производства биогаза путем предварительной обработки соломы 0,25 и 0,5 масс. карбонатом натрия $\left(\mathrm{Na}_{2} \mathrm{CO}_{3}\right)$ при температуре $90^{\circ} \mathrm{C}, 110^{\circ} \mathrm{C}$ и $130^{\circ} \mathrm{C}$ в течение 1 , 2 и 3 ч. с последующим метановым брожением в мезофильном режиме $\left(37^{\circ} \mathrm{C}\right)$ исследовано в работе [25]. Повышение концентрации карбоната натрия существенно улучшил выход биогаза, тогда как влияние времени обработки показал меньшее влияние. Наилучшие результаты были получены предварительной обработкой 0,5 масс. карбонатом натрия при $110^{\circ} \mathrm{C}$ в течение 2 ч., привели к получению 292 мл $\mathrm{CH}_{4} / \Gamma \mathrm{VS}$, тогда как при сбраживании необработанной рисовая солома выход биометана составил 130 мл $\mathrm{CH}_{4} / \Gamma \mathrm{VS}$.

Анализ проведенных исследований показывает, что требуется дальнейшее изучение вопросов интенсификации выхода биогаза и выработки электроэнергии на основе сбраживания навоза КРС со стимулирующими добавками. При этом в рассмотренных выше работах оценка выхода биогаза осуществлялась только по данным экспериментальных исследований без учета влияния экструзии соломы на выход биогаза. Кроме того, в работах не показаны рациональные (оптимальные) соотношения соломы и гашеной извести, при которых обеспечивается максимальный выход биогаза, a, следовательно, выработки электроэнергии.

Одним из подходов к устранению указанных недостатков является проведение экспериментальных исследований при периодической загрузке субстратов для определения оптимального соотношения соломы и гашеной извести.

\section{III. МЕТОДИКА ИССЛЕДОВАНИЙ}

Определение интенсивности метанового брожения пеллет соломы пшеницы осуществлялось в зависимости от обработки раствором $\mathrm{Ca}(\mathrm{OH})_{2}$ разной концентрации $(50$ кг $\mathrm{CaO} /$ т соломы, 100 кг $\mathrm{CaO} /$ т соломы, 150 кг $\mathrm{CaO} /$ т соломы), способа замачивания в растворе $\mathrm{Ca}(\mathrm{OH})_{2}$ (перед экструзией, во время экструзии, после экструзии).

Замачивания проводилось 5 мин. при температуре $20^{\circ} \mathrm{C}$.

Измерение объема биогаза во всех опытах осуществлялось по методу Криворучко.

Для проведения опыта использовались полиэтиленовые пакеты (ферментеры), устройство для запайки пакетов, $\mathrm{pH}$-метр, калиброванный цилиндр.

К рассчитанному количеству биомассы добавляли затравку из расчета 1 часть пробы до 4 частей затравки, вытесняли воздух из ферментера и герметично запаивали отверстие.

К запаянному пакету подвешивали гирю, а пакет опускали в измерительный цилиндр. Таким образом определялся первоначальный объем исследуемого варианта. После этого пакет подвешивали в термостат и выдерживали там при температуре $37,5^{\circ} \mathrm{C}$ не менее 35 суток.

Измерение объема пакетов проводили через каждые семь дней. Объектами исследований были: солома пшеницы с Козовского района Тернопольской области (сухое вещество (СВ) - 86,94\%) и затравка (навоз крупного рогатого скота), которая была предварительно профильтрована через сито.

Схема технологического приготовления сырья (соломы пшеницы) для опытов и определения оптимального соотношения соломы и гашеной извести изображена на рис. 1. 


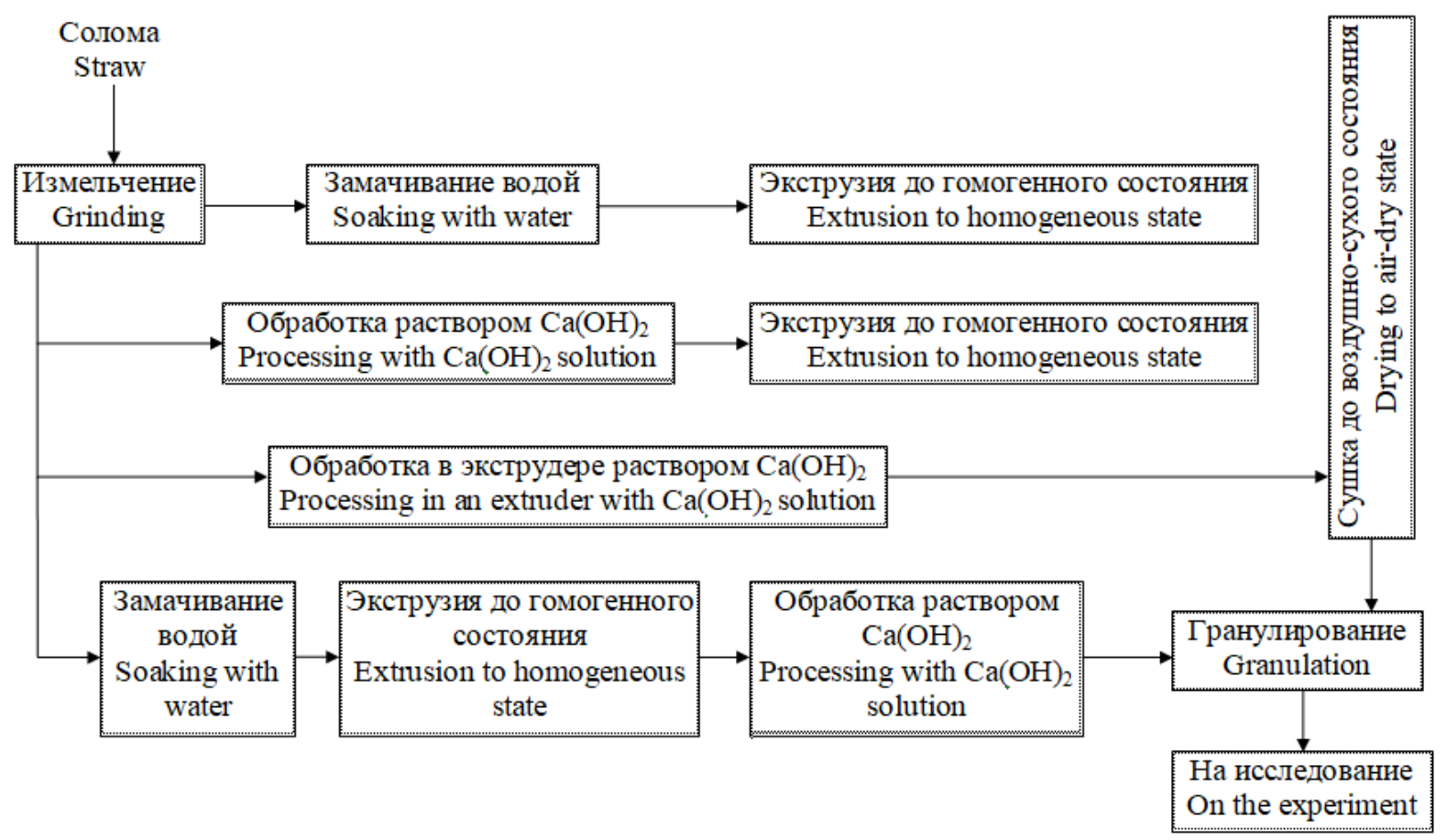

Рис. 1. Схема технологического процесса приготовления сырья (соломы пшеницы) для опытов. ${ }^{1}$

IV. РЕЗУЛЬТАТЫ И ОБСУЖДЕНИЕ

Исследование выхода биогаза при сбраживании навоза КРС с добавлением пеллет экструдированной соломы пшеницы и гашеной извести.

Новизна выбранной темы состоит в использовании химической обработки биомасы в сочетании с экструзией. При экструзии проходит дополнительная термохимическая обработка. Преимущество использования пеллет экструдированной соломы пшеницы заключается в том, что такое сырье лучше транспортируется на большие расстояния или хранится на складе (меньший объем при транспортировке и меньше площади для складирования). Пеллеты целесообразны для непрерывной работы биогазовых установок, поскольку отходы сельскохозяйственного производства имеют сезонный характер.

Результаты исследований показали, что предварительная обработка соломы пшеницы различной концентрации $\mathrm{Ca}(\mathrm{OH})_{2}$ приводит к расщеплению лигниноцеллюлозы, увеличению выхода биогаза (табл. 1) и выработки электроэнергии.

Таким образом, на основе полученных результатов экспериментальных исследований необходимо найти из множества возможных вариантов $(X)$ такой технологический вариант добавления гашеной извести к соломе $(x)$, при котором обеспечивается максимальный выход биогаза и электроэнергии при заданной стоимости входного субстрата (C). При этом предполагается, что добавление извести в пеллеты соломы представляет собой управляемый $N$-этапный динамический процесс, который на каждом (n-м) этапе характеризуется двумя видами параметров: параметрами управления $m_{n}$ (объемом загрузки $n$-го вида биомассы и извести), а также параметрами состояния $G_{n}\left(m_{n}\right)$ (выходом биогаза и электроэнергии на $n$-м этапе технологического процесса). В виде ограничений выступает стоимость входного субстрата $(C)$.

Конечной целью технологического процесса подготовки входного сырья для БГУ $\left(W_{N}\right)$ является получение максимальных объемов биогаза и электроэнергии.

В общем случае задача оптимизации технологического процесса по подготовке пеллет из различных видов сырья может быть представлена следующим образом.

$$
\max W_{N}=\sum_{n=1}^{N} G_{n}\left(m_{n}\right)
$$

при $C_{N} \leq C$, 
Выход биогаза, м $^{3} /$ кг СВ (нормальные условия).

Biogas output, $\mathrm{m}^{3} / \mathrm{kg}$ dry matter (normal conditions).

\begin{tabular}{|c|c|c|c|c|c|c|c|}
\hline \multirow[b]{2}{*}{$\begin{array}{l}\text { № } \\
\text { п/ா }\end{array}$} & \multirow{2}{*}{$\begin{array}{c}\text { Способы обработки соломы } \\
\text { Straw processing methods }\end{array}$} & \multirow{2}{*}{$\begin{array}{c}\text { Масса } \\
\text { Са(ОН })_{2} \\
\text { кг/т соломы } \\
\text { Mass of } \\
\text { Ca(OH })_{2} \\
\text { kg/t of straw }\end{array}$} & \multicolumn{5}{|c|}{ Day (день) } \\
\hline & & & 7 & 14 & 21 & 28 & 35 \\
\hline 1 & $\begin{array}{l}\text { Пеллеты экструдированной } \\
\text { соломы пшеницы } \\
\text { Extruded wheat straw pellets }\end{array}$ & 178 & 0,178 & 0,186 & 0,229 & 0,235 & 0,245 \\
\hline 2 & \multirow{3}{*}{$\begin{array}{l}\text { Пеллеты экструдированной } \\
\text { соломы с Са(OH) } \\
\text { Extruded wheat straw pellets with } \\
\mathrm{Ca}(\mathrm{OH})_{2} \text { before extrusion }\end{array}$} & 193 & 0,193 & 0,259 & 0,293 & 0,293 & 0,293 \\
\hline 3 & & 255 & 0,255 & 0,326 & 0,327 & 0,327 & 0,327 \\
\hline 4 & & 246 & 0,246 & 0,303 & 0,303 & 0,303 & 0,317 \\
\hline 5 & \multirow{3}{*}{$\begin{array}{l}\text { Пеллеты экструдированной } \\
\text { соломы с } \mathrm{Ca}(\mathrm{OH})_{2} \text { во время } \\
\text { экструзии } \\
\text { Extruded wheat straw pellets with } \\
\text { с } \mathrm{Ca}(\mathrm{OH})_{2} \text { during extrusion }\end{array}$} & 251 & 0,251 & 0,355 & 0,355 & 0,377 & 0,377 \\
\hline 6 & & 291 & 0,291 & 0,393 & 0,393 & 0,395 & 0,395 \\
\hline 7 & & 284 & 0,284 & 0,352 & 0,360 & 0,399 & 0,399 \\
\hline 8 & \multirow{3}{*}{$\begin{array}{l}\text { Пеллеты экструдированной } \\
\text { соломы с Са }(\mathrm{OH})_{2} \text { после } \\
\text { экструзии } \\
\text { Extruded wheat straw pellets with } \\
\mathrm{Ca}(\mathrm{OH})_{2} \text { after extrusion }\end{array}$} & 235 & 0,235 & 0,263 & 0,311 & 0,330 & 0,330 \\
\hline 9 & & 283 & 0,283 & 0,337 & 0,342 & 0,342 & 0,342 \\
\hline 10 & & 209 & 0,209 & 0,302 & 0,315 & 0,331 & 0,331 \\
\hline
\end{tabular}

где $C_{N}-$ суммарные стоимостные затраты каждого вида сырья на протяжении $N$ этапов технологического процесса.

С учетом дискретного описания процесса планирования расхода различных видов сырья целевая функция эффективности функционирования БГУ $\left(W_{N}\right)$ может быть представлена сумою

$$
W_{N}=\sum_{n=1}^{N} G_{n}\left(m_{n}\right)
$$

где $G_{n}\left(m_{n}\right)$ - выход биогаза и электроэнергии на $n$-м этапе технологического процесса; $m_{n}$ - объем загрузки $n$-го вида биомассы и извести БГУ; $N$ - общее количество этапов.

Таким образом, необходимо найти такие объемы различных видов сырья на каждом этапе, чтобы максимизировать целевую функцию (3) при следующих ограничениях:

$$
\begin{array}{rr}
\text { a) } m_{n}=0,1,2, \ldots, \\
\text { b) } \sum_{n=1}^{N} c_{n} m_{n} \leq C, \\
\text { где } c_{n}-\text { стоимость } \quad n \text {-го вида }
\end{array}
$$

биомассы.

Для определения оптимальных значений $\left\{m_{n}\right\}$ воспользуемся методом динамического программирования.

Обозначим

$$
\max _{m_{1}, \ldots, m_{r}} \sum_{n=1}^{r} G_{n}\left(m_{n}\right)
$$

при условии

$$
\sum_{n=1}^{r} \tilde{n}_{n} m_{n} \leq \xi
$$

через $\Lambda_{r}(\xi)$.

После несложных преобразований переходим к следующему рекуррентному соотношению динамического программирования

$$
\begin{aligned}
& \Lambda_{r}(\xi)=\max _{m_{r}}\left\{G_{r}\left(m_{r}\right)+\Lambda_{r-1}\left(\xi-t_{r} m_{r}\right)\right\} \\
& (r=1, \ldots, N)
\end{aligned}
$$

при условии

$$
0 \leq m_{r} \leq \frac{\xi}{\tilde{n}_{r}} .
$$

Характерным

$$
\text { для }
$$

метода динамического программирования является определенный методический прием, a именно: процесс подготовки сырья для БГУ 
делится на $N$ этапов и осуществляется последовательная оптимизация каждого из них. На каждом $r$-м этапе с учетом всех возможных предположений результатов предыдущего этапа определяется основное рекуррентное соотношение (7) и рассчитывается условный оптимальный параметр управления $m_{r}$.

Если предположить, что $\xi=C$ и $r=N$, получаем следующее соотношение

$$
\Lambda_{N}(\xi=C)=\max _{m_{N}}\left\{G_{N}\left(m_{N}\right)+\Lambda_{N-1}\left(C-c_{N} m_{N}\right)\right\}
$$

при условии

$$
0 \leq m_{N} \leq \frac{C}{c_{N}}
$$

Найдя с (9) оптимальное значение $m_{N o p t}$ при условии $\xi_{1}=C-c_{N} m_{N o p t}(N)$, последовательно, начиная с $(N-1)$-го этапа, определяются оптимальные значения остальных переменных: $m_{N-1}, m_{N-2}, \ldots, m_{1}$.

Зависимость выхода биогаза в зависимости от технологии подготовки пеллет соломы пшеницы с обработкой раствором $\mathrm{Ca}(\mathrm{OH})_{2}$ (до, во время, после экструзии), изображена на диаграммах (рис. 2-4).

Динамика газообразования показывает резкий рост активности за 14 суток и следующий спад. Можно заметить, что динамика образования биогаза меняется не плавно: есть периоды затухания, а затем увеличения выделения биогаза. За 35 суток процесс образования газа в большинстве случаев заканчивается (см. рис. 2-4). Наибольший выход биогаза получено из пеллет экструдированной соломы пшеницы, которая обработана раствором $\mathrm{Ca}(\mathrm{OH})_{2}$ (из расчета 150 кг $\mathrm{CaO} / \mathrm{T}$ соломы) во время экструзии - 0,399 м³/кг, что на $63 \%$ больше выхода биогаза из пеллет экструдированной соломы пшеницы, которые не обрабатывалась раствором гашеной извести.

Проанализируем подробнее способы обработки гашеной известью. При обработке соломы пшеницы до экструзии выход биогаза увеличился: при концентрации раствором $\mathrm{Ca}(\mathrm{OH})_{2} 50$ кг $\mathrm{CaO} / \mathrm{T}$ - на 20\%, 100 кг $\mathrm{CaO} / \mathrm{T}-33 \%, 150$ кг $\mathrm{CaO} / \mathrm{T}-29 \%$ (рис. 2).

Из рис. 2 видно, что наибольший выход метана $\left(0,327 \mathrm{~m}^{3} /\right.$ кг СВ) получено от пеллет соломы пшеницы, которые обрабатывались до экструзии раствором $\mathrm{Ca}(\mathrm{OH})_{2}$ из расчета 100 кг $\mathrm{CaO} / \mathrm{T}$ (на 33\% больше контрольного опыта).

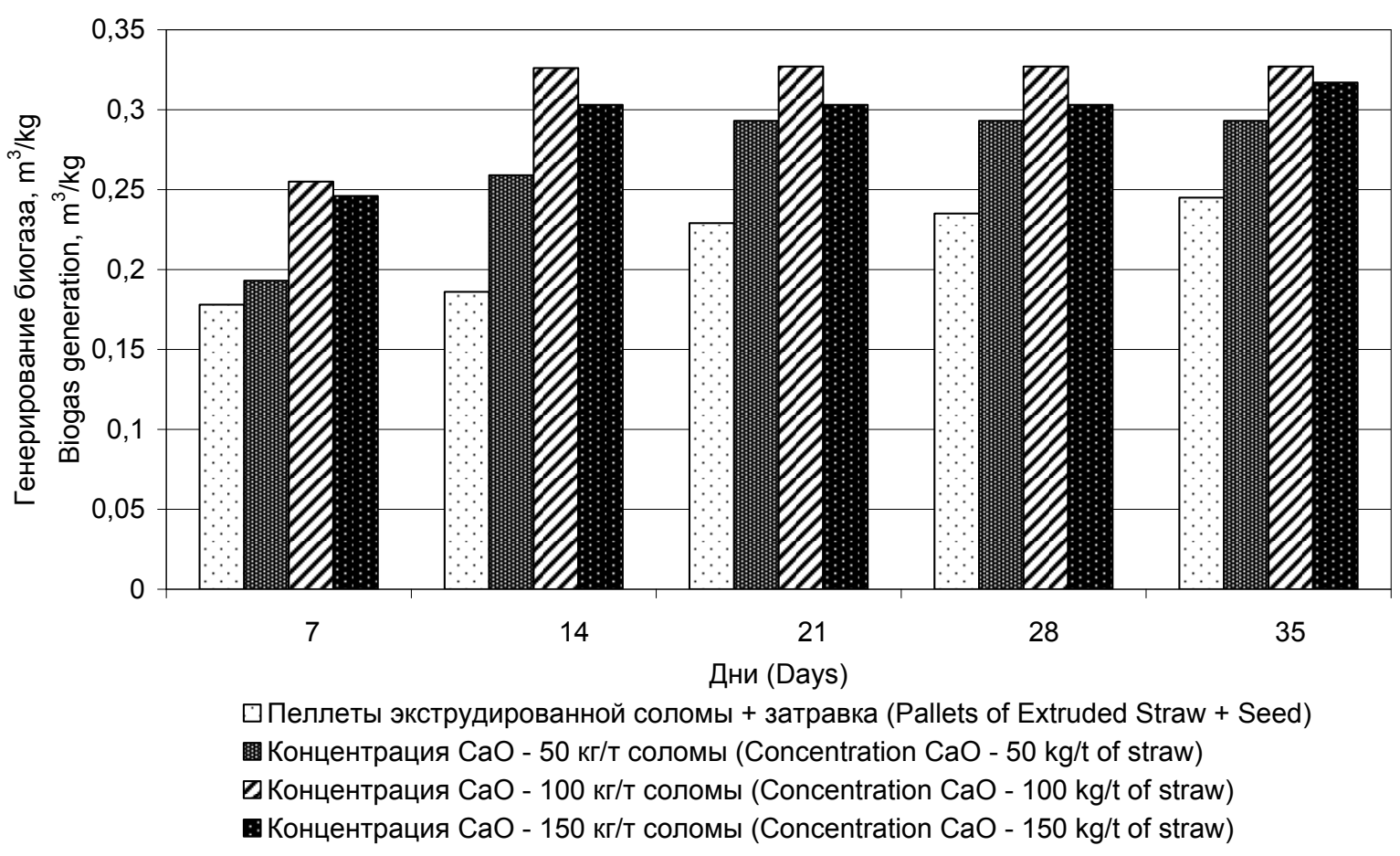

Рис. 2. Зависимость выхода биогаза от предварительной обработки пшеничной соломы раствором $\mathrm{Ca}(\mathrm{OH})_{2}$ с разной концентрацией $\left(50\right.$ кг/т $\mathrm{CaO}, 100$ кг/т $\mathrm{CaO}, 150$ кг/т СаO). ${ }^{3}$ 
При обработке соломы пшеницы при экструзии выход биогаза увеличился: при концентрации раствором $\mathrm{Ca}(\mathrm{OH})_{2} 50$ кг $\mathrm{CaO} / \mathrm{T}$ - на 54\%, 100 кг $\mathrm{CaO} / \mathrm{T}$ - 61\%, 150 кг $\mathrm{CaO} /$ т $63 \%$ (рис. 3 ).

Из приведенной диаграммы видно, что

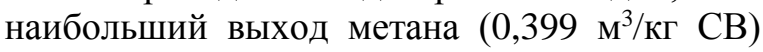
получено от пеллет соломы пшеницы, которые обрабатывались при экструзии раствором $\mathrm{Ca}(\mathrm{OH})_{2}$ из расчета 100 кг $\mathrm{CaO} / \mathrm{T}$ (на 63\% больше контрольного опыта).

Обработка соломы пшеницы после экструзии раствором $\mathrm{Ca}(\mathrm{OH})_{2}$ с разной концентрацией увеличивает выход биогаза: при концентрации раствора $\mathrm{Ca}(\mathrm{OH})_{2}$ с расчетом 50 кг $\mathrm{CaO} /$ т - на 35\%, 100 кг $\mathrm{CaO} /$ т $40 \%, 150$ кг $\mathrm{CaO} / \mathrm{T}-35 \%$.

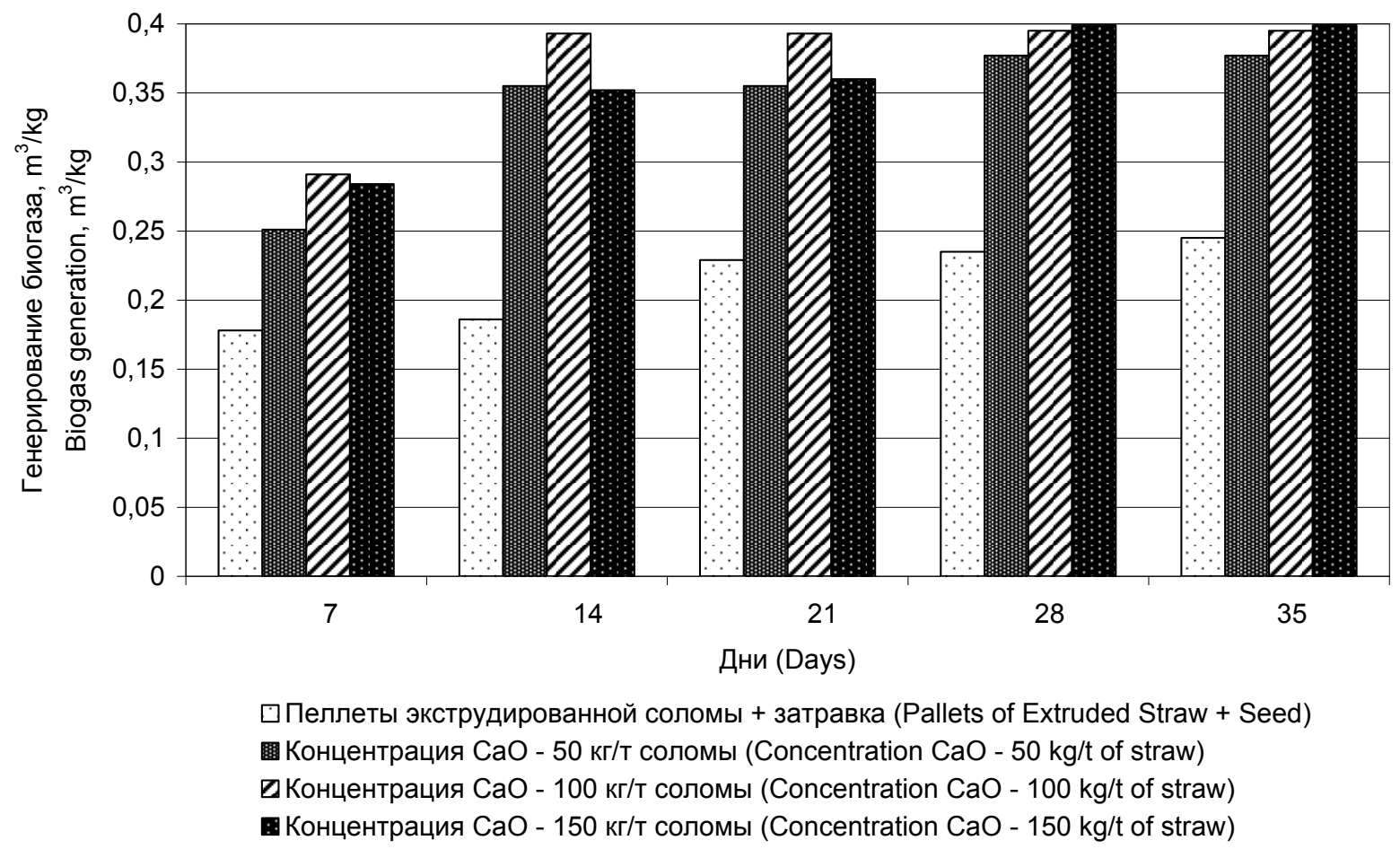

Рис. 3. Зависимость выхода биогаза от непосредственной обработки в экструдере до гомогенного состояния соломы пшеницы раствором $\mathrm{Ca}(\mathrm{OH})_{2}$ с разной концентрацией $\left(50\right.$ кг/т CaO, 100 кг/т CaO, 150 кг/т СaO). ${ }^{4}$

На рис. 4 показана зависимость выхода биогаза от экструдированной до гомогенного состояния пшеничной соломы раствором $\mathrm{Ca}(\mathrm{OH})_{2}$ с разной концентрацией $(50$ кг/т $\mathrm{CaO}, 100$ кг/т $\mathrm{CaO}, 150$ кг/т).

Необходимо отметить, что метод динамического программирования представляет собой такой направленный последовательный перебор вариантов, который обязательно приводит к глобальному максимуму и оптимальному решению задачи (1).

Оптимальная загрузка из расчета 100 кг $\mathrm{CaO} / \mathrm{T}$ в реактор в виде пеллет соломы имеет значительные преимущества и является оптимальным решением поскольку выход биогаза в этом случае практически не отличается от выхода, который получен из пеллет соломы пшеницы из расчета 150 кг
$\mathrm{CaO} / \mathrm{T}$ соломы, но является более экономически выгодным. Кроме того, целогодичное использование пеллет соломы с оптимальной добавкой гашеной извести для БГУ позволяет получить качественные биологические органические удобрения; обеспечить высокую стабильную и безаварийную работу всей системы в целом; повысить газоотдачу из биосырья растительного происхождения (солома, трава, кормовые отходы и т. д.) за счет разложения целлюлозы. При этом проще осуществляется переход на другие виды сырья, а также повышается удельная загрузка всей линии. Из проведенных расчетов видно, что наибольший выход метана $\left(0,342 \mathrm{~m}^{3} /\right.$ кг СВ) получен из пеллет соломы пшеницы, которые обрабатывались после экструзии раствором $\mathrm{Ca}(\mathrm{OH})_{2}$ из расчета 100 кг $\mathrm{CaO} / \mathrm{T}$ (на $40 \%$ 
больше контрольного опыта).

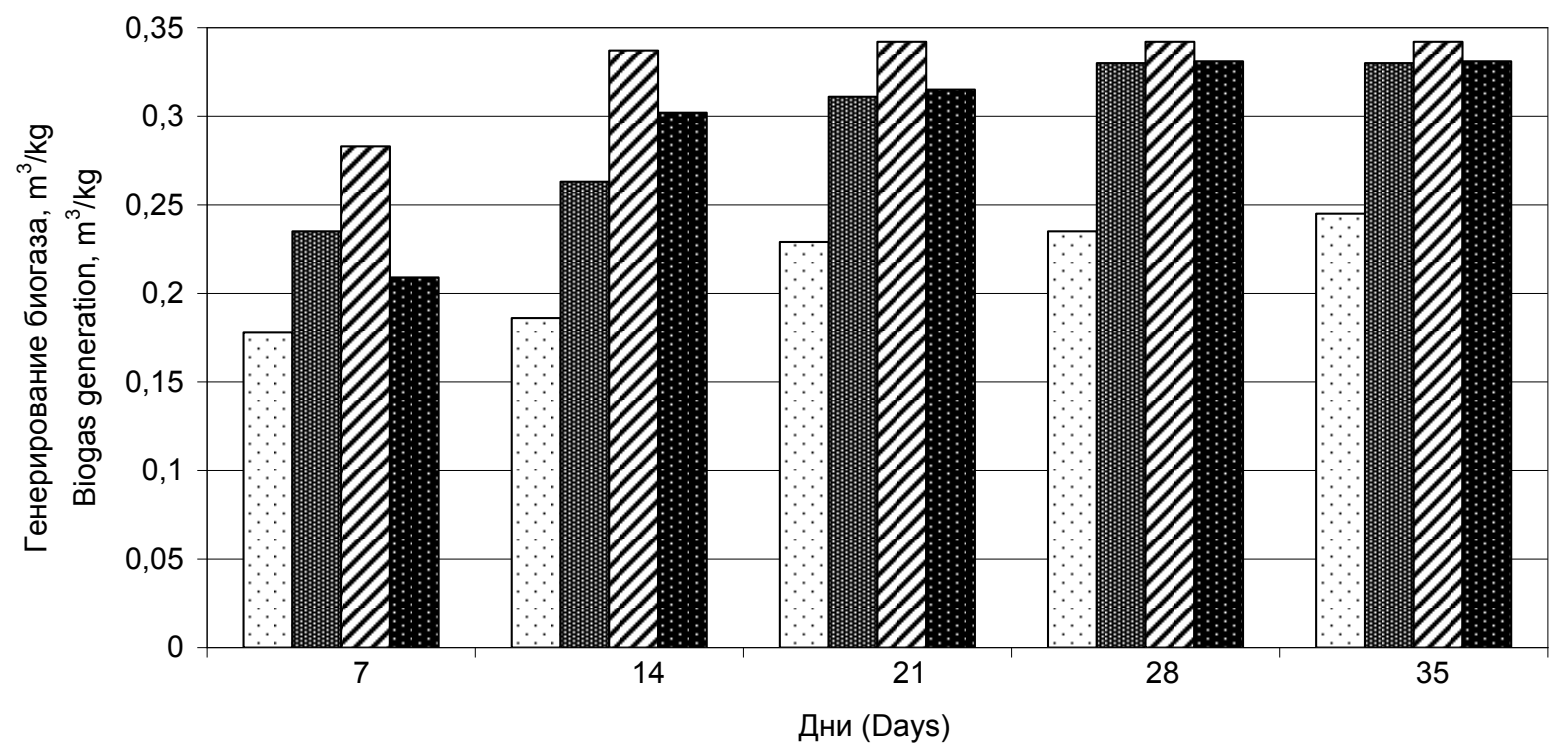

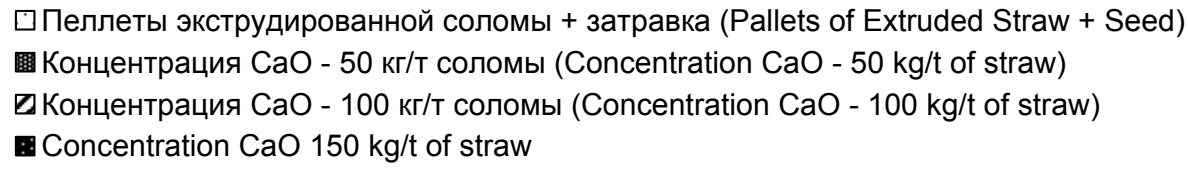

Рис. 4. Зависимость выхода биогаза от экструдированной до гомогенного состояния пшеничной соломы раствором Са $(\mathrm{OH})_{2}$ с разной концентрацией $(50 \mathrm{\kappa г} / \mathrm{T} \mathrm{CaO}$, 100 кг/т СаO, 150 кг/т). ${ }^{5}$

При этом, выход биогаза из навоза крупного рогатого скота составляет $0,25-0,34$ $\mathrm{m}^{3} /$ кг СВ при содержании биометана $65 \%$ [26]. То есть, выход биометана при сбраживании навоза крупного рогатого скота (без использования пеллет) - 0,16-0,22 м³ $/$ кг СВ.

Значимость результатов исследований состоит в том, что оптимальное использование экструдированной совместно с известью соломы в качестве косубстрата позволит увеличить выход биогаза и электроэнергии более чем на $60 \%$ по сравнению со сбраживанием необработанной соломы, и на $30-50 \%$ по сравнению со сбраживанием коровьего навоза.

При сбраживании гранул с известью, изготовленных из соломы, собранной с площади 10 тыс. га, период окупаемости биогазового комплекса будет составлять 6,7 лет (рис. 5), что ниже периода окупаемости биогазового комплекса, который работает лишь на экструдированной соломе ( 8,2 года) или на измельченной соломе (11,2 года).

\section{V. ВЫВОДЫ}

1. Предварительная щелочная обработка лигниноцелюлозных материалов является перспективной обработкой для внедрения в производство биогаза. Лучший выход биогаза получено из пеллет экструдированной соломы пшеницы, которые обрабатывались раствором $\mathrm{Ca}(\mathrm{OH})_{2}$ (из расчета 150 кг $\mathrm{CaO} / \mathrm{T}$ соломы пшеницы) во время экструзии ( 0,4 $\mathrm{m}^{3} /$ кг СВ), что на $63 \%$ больше выхода биогаза, полученного из контрольной пробы (необработанная солома). Выход биогаза из пеллет соломы пшеницы, которая обрабатывалась раствором $\mathrm{Ca}(\mathrm{OH})_{2}$ из расчета 50 кг $\mathrm{CaO} /$ т соломы в экструзии, по сравнению с другими концентрациями, является самым низким. На основе использования метода динамического программирования найдена оптимальная концентрация раствора $\mathrm{Ca}(\mathrm{OH})_{2}$ для внедрения в производство - 100 кг $\mathrm{CaO} / \mathrm{T}$ соломы $(+61 \%)$, поскольку выход биогаза практически не отличается от выхода, который получен из пеллет соломы пшеницы из расчета 150 кг $\mathrm{CaO} /$ т соломы $(+63 \%)$, но является более экономически выгодным.

2. Преимуществами предварительной щелочной обработки лигниноцеллюлозных материалов являются:

- увеличение выхода биогаза;

- сравнительно низкая стоимость материала;

- возможность использования шлама (твердых и жидких отходов) как 
биоминерализованого удобрения;

- выделение «нейтрального» $\mathrm{CO}_{2}$;

- сравнительно невысокие

квалификационные требования к обслуживающему персоналу.

Предварительная обработка улучшает биодоступность отходов для производства биогаза и увеличивает уровень доступности материалов для действия бактерий. Результатом этого процесса является обогащение материалов, которые трудно поддаются конверсии для повышения эффективности производства биогаза из отходов.

3. Наиболее значимый результат исследований состоит в том, что найдено оптимальное соотношение экструдированной совместно с известью соломы в качестве косубстрата, что позволит увеличить выход биогаза и электроэнергии более чем на 60\% по сравнению со сбраживанием необработанной соломы, и на $30-50 \%$ по сравнению со сбраживанием коровьего навоза.

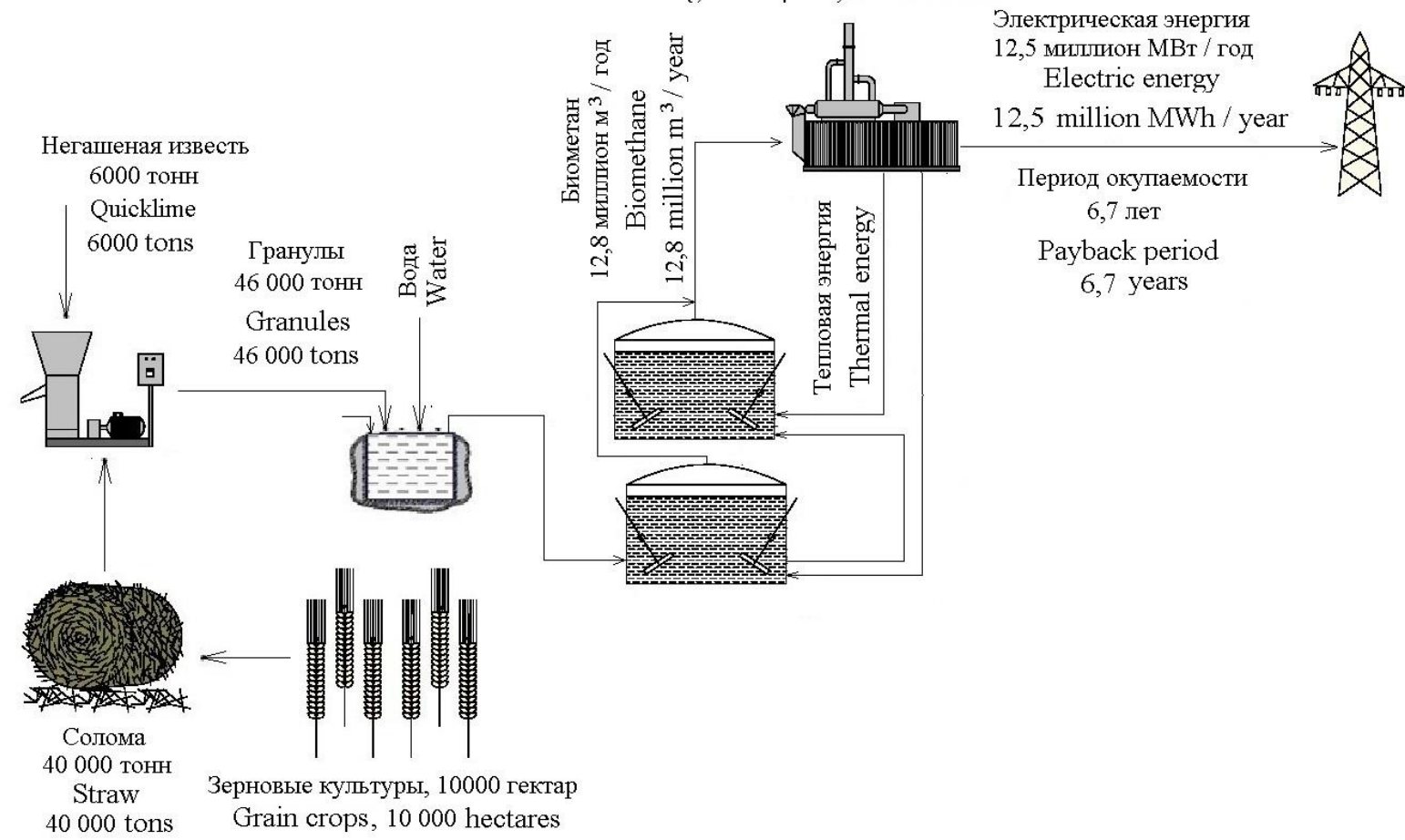

Биогазовьй комплекс, $\mathrm{P}=3467 \mathrm{MBT}$

Biogas complex, $\mathrm{P}=3467 \mathrm{MW}$

Рис. 5. Схема производства биогаза из гранулированной соломы с добавлением извести с выработкой тепловой и электрической энергии. ${ }^{6}$

\section{Appendix 1}

1Fig. 1. Scheme of the technological process of preparing raw materials (wheat straw) for experiments.

${ }^{3}$ Fig. 2. Dependence of biogas yield on pretreatment of wheat straw with $\mathrm{Ca}(\mathrm{OH})^{2}$ solution with different concentrations (50 kg/t CaO, $100 \mathrm{~kg} / \mathrm{t} \mathrm{CaO}, 150 \mathrm{~kg} / \mathrm{t} \mathrm{CaO}$ ).

${ }^{4}$ Fig. 3. Dependence of biogas yield on direct processing in an extruder to a homogeneous state of wheat straw with a $\mathrm{Ca}(\mathrm{OH})^{2}$ solution with different concentrations $(50 \mathrm{~kg} / \mathrm{t} \mathrm{CaO}, 100 \mathrm{~kg} / \mathrm{t} \mathrm{CaO}, 150 \mathrm{~kg} / \mathrm{t} \mathrm{CaO})$.

${ }^{5}$ Fig. 4. Dependence of biogas yield on wheat straw extruded to a homogeneous state with $\mathrm{Ca}(\mathrm{OH})^{2}$ solution with different concentration $(50 \mathrm{~kg} / \mathrm{t} \mathrm{CaO}$, $100 \mathrm{~kg} / \mathrm{t} \mathrm{CaO}, 150 \mathrm{~kg} / \mathrm{t})$.

${ }^{6}$ Fig. 5. Scheme of biogas production from granulated straw with the addition of lime with the production of heat and electricity.

${ }^{2}$ Table 1. Biogas output, $\mathrm{m} 3 / \mathrm{kg}$ dry matter (normal conditions).

\section{Библиография (References)}

[1] Novakovic, J., Kontogianni, N., Barampouti, E.M., Mai, S., Moustakas, K., Malamis, D., Loizidou, M. Towards upscaling the valorization of wheat straw residues: alkaline pretreatment using sodium hydroxide, enzymatic hydrolysis and biogas production. Environmental science and pollution research. 2020. Early access: JUN 2020. doi: 10.1007/s11356-020-08905-y.

[2] Kontogianni, N., Barampouti, E.M., Mai, S., Malamis, D., Loizidou, M. Effect of alkaline pretreatments on the enzymatic hydrolysis of wheat straw. Environmental Science and Pollution Research. 2019. Vol. 26, Iss. 35, SI. P. 35648-35656. doi: 10.1007/s11356-019-06822-3.

[3] Dai, B.L., Guo, X.J., Yuan, D.H., Xu, J..M. 
Comparison of Different Pretreatments of Rice Straw Substrate to Improve Biogas Production. Waste And Biomass Valorization. 2018. Vol. 9, Iss. 9. P. 1503-1512. doi: 10.1007/s12649-017-9950-9.

[4] Paritosh, K., Balan, V., Vijay, V.K., Vivekanand, V. Simultaneous alkaline treatment of pearl millet straw for enhanced solid state anaerobic digestion: Experimental investigation and energy analysis. Journal of Cleaner Production. 2020. Vol. 252. Article number: 119798. doi: 10.1016/j.jclepro.2019.119798.

[5] Liu, R., Zhang, X., Sun, W.X., Zou, H., Zheng, Y., Zhang, G.S., Wang, Z.Y., Fu, S.F. SolidState KOH Pretreatment of Corn Straw for Anaerobic Digestion: Methane Yield Enhancement, Potassium Flow Analysis, and Preliminary Economic Assessment. Energy \& Fuels. 2019. Vol. 33, Iss. 11. P. 11034-11040. doi: 10.1021/acs.energyfuels.9b0240S.

[6] Jaffar, M. Yuan, H.R., Zou, D.X., Liu, Y.P., Korai, R.M., Pang, Y.Z., Li, X.J. Wheat straw pretreatment with potassium hydroxide for enhanced biogasification and fertilizer value. Fresenius Environmental Bulletin. 2015. Vol. 24, Iss. 10B. P. 3491-3498.

[7] Korai, R.M., Wachemo, A.C., Yue, L., Jaffar, M., Li, Z., Shahbaz, M., Yuan, H., Li, X. Effect of ultrasonic application during $\mathrm{KOH}$ pretreatment and anaerobic process on digestion performance of wheat straw. RSC Advances. 2020. Vol. 10, Iss. 16. P. 9290-9298. doi: 10.1039/d0ra00525h.

[8] Jaffar, M., Pang, Y.Z., Yuan, H.R., Zou, D.X., Liu, Y.P., Zhu, B.N., Korai, R.M., Li, X.J. Wheat straw pretreatment with $\mathrm{KOH}$ for enhancing biomethane production and fertilizer value in anaerobic digestion. Chinese Journal of Chemical Engineering. 2016. Vol. 24, Iss. 3. P. 404-409. doi: 10.1016/j.cjche.2015.11.005.

[9] Guan, R.L., Gu, J.Y., Wachemo, A.C., Yuan, H.R., Li, X.J. Novel Insights into Anaerobic Digestion of Rice Straw Using Combined Pretreatment with $\mathrm{CaO}$ and the Liquid Fraction of Digestate: Anaerobic Digestion Performance and Kinetic Analysis. For results 2th International Symposium on Biomass/Wastes Energy and Environment (BEE) (May 23-26, 2019, Tianjin, China), Energy \& Fuels, 2020. Vol. 34, Iss. 2. P. 1119-1130. doi: 10.1021/acs.energyfuels.9b02104.

[10] Yuan, Y., Bian, A.Q., Zhang, L.L., Chen, Z.L., Zhou, F., Ye, F., Jin, T.L., Pan, M., Chen, T.M., Yan, J.L., Wang, A.J., Li, Z.X., Ding, C. Thermal-alkali and Enzymes for Efficient Biomethane Production from Co-digestion of Corn straw and Cattle Manure. Bioresources. 2019. Vol. 14, Iss. 3. P. 5422-5437. doi: 10.15376/biores.14.3.5422-5437.

[11] Du, J., Qian, Y.T., Xi, Y.L., Lu, X.W. Hydrothermal and alkaline thermal pretreatment at mild temperature in solid state for physicochemical properties and biogas production from anaerobic digestion of rice straw. Renewable Energy. 2019. Vol. 139. P. 261-267. doi: 10.1016/j.renene.2019.01.097.
[12] Kumar, S., Gandhi, P., Yadav, M., Paritosh, K., Pareek, N., Vivekanand, V. Weak alkaline treatment of wheat and pearl millet straw for enhanced biogas production and its economic analysis. Renewable Energy. 2019. Vol. 139. P. 753-764. doi: 10.1016/j.renene.2019.02.133.

[13] Qiao, W.C., Liu, H., Zhang, Y.H., Miao, J.H., Tang, T.H., Yang, Q.W. Structural Characterization of the Biogas Fermentation Residue from Wheat Straw. Journal of Biobased Materials And Bioenergy. 2019. Vol. 13, Iss. 2. P. 188-194. doi: 10.1166/jbmb.2019.1831.

[14] Noonari, A.A., Mahar, R.B., Sahito, A.R., Brohi, K.M. Optimization of Methane Production from Rice Straw and Buffalo Dung by $\mathrm{H}_{2} \mathrm{O}_{2}$ and $\mathrm{Ca}(\mathrm{OH})_{2}$ : Pretreatments and Its Kinetics. Waste And Biomass Valorization. 2019. Vol. 1, Iss. 4. P. 899-908. doi: 10.1007/s12649-017-0102-z.

[15] Guan, R.L., Li, X.J., Wachemo, A.C., Yuan, H.R., Liu, Y.P., Zou, D.X., Zuo, X.Y., Gu, J.Y. Enhancing anaerobic digestion performance and degradation of lignocellulosic components of rice straw by combined biological and chemical pretreatment. Science of The Total Environment. 2018. Vol. 637. P. 9-17. doi: 10.1016/j.scitotenv.2018.04.366.

[16] Sato, A., Widjaja, A., Asror, K., Emilia, A.R. Influence of alkaline addition on the composition and yield on the hydrothermal treatment of rice straw. Malaysian Journal of Fundamental And Applied Sciences. 2019. Vol. 15, Iss. 4. P. 537-542.

[17] Sato, A., Soeprijanto, Widjaja, A. Influence of Alkaline Hydrothermal Pretreatment of Rice Straw on Biomass Composition. International Energy Journal. 2019. Vol. 19, Iss. 2. P. 115124.

[18] Fjortoft, K., Morken, J., Hanssen, J.F., Briseid, T. Pre-treatment methods for straw for farmscale biogas plants. Biomass \& Bioenergy. 2019. Vol. 124. P. 88-94. doi: 10.1016/j.biombioe.2019.03.018.

[19] Mancini, G., Papirio, S., Riccardelli, G., Lens, P.N.L., Esposito, G. Trace elements dosing and alkaline pretreatment in the anaerobic digestion of rice straw. Bioresource Technology. 2018. Vol. 247. P. 897-903. doi: 10.1016/j.biortech.2017.10.001

[20] Vasmara, C., Cianchetta, S., Marchetti, R., Galletti, S. Biogas Production from wheat straw pretreated with hydrolytic enzymes or sodium hydroxide. Environmental Engineering And Management Journal. 2017. Vol. 16, Iss. 8. P. 1827-1835. doi: 10.30638/eemj.2017.199.

[21] Janke, L., Weinrich, S., Leite, A.F., Terzariol, F.K., Nikolausz, M., Nelles, M., Stinner, W. Improving anaerobic digestion of sugarcane straw for methane production: Combined benefits of mechanical and sodium hydroxide pretreatment for process designing. Energy Conversion And Management. 2017. Vol. 141, SI. P. 378-389. doi: 10.1016/j.enconman.2016.09.083.

[22] Shetty, D.J., Kshirsagar, P., Tapadia- 
Maheshwari, S., Lanjekar, V., Singh, S.K., Dhakephalkar, P.K. Alkali pretreatment at ambient temperature: A promising method to enhance biomethanation of rice straw. Bioresource Technology. 2017. Vol. 226. P. 8088. doi: 10.1016/j.biortech.2016.12.003.

[23] Chufo, A., Yuan, H.R., Zou, D.X., Pang, Y.Z., Li, X.J. Biomethane production and physicochemical characterization of anaerobically digested teff (Eragrostis tef) straw pretreated by sodium hydroxide. Bioresource Technology. 2015. Vol. 181. P. 214-219. doi: 10.1016/j.biortech.2015.01.054.

[24] Hashemi, S.S., Karimi, K., Nosratpour, M.J., Horvath, I.S. Efficient Biogas and Ethanol

\section{Сведения об авторах.}

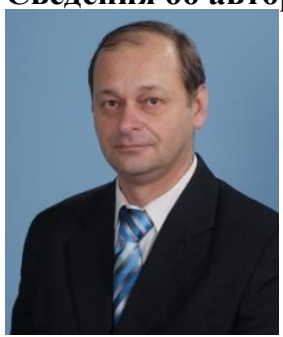

Полищук Виктор

Николаевич. Национальный университет биоресурсов и природопользования Украины, кафедра охраны труда и инженерии среды, доктор технических наук, доцент. Основная область исследований: технологии и технические средства производства биотоплива.

E-mail:

polischuk.v.m@gmail.com

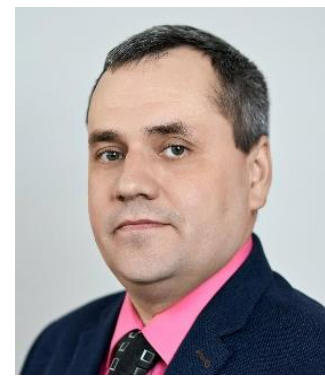

Фльонц Игорь Владимирович. Национальный университет биоресурсов

и

природопользования Украины, Обособленное подразделение "Бережанский агротехнический институт",

энергетических машин технического сервиса в АПК, кандидат технических наук, доцент. Основная область исследований: технологии и технические средства производства и использования биотоплива.

E-mail: flonc_igor@ukr.net

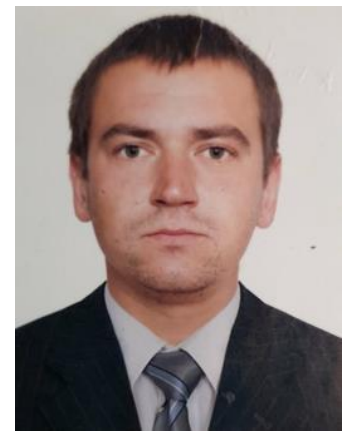

Дворнык Евгений Алексеевич. Национальный университет биоресурсов и природопользования Украины, кафедра технического сервиса и инженерного менеджмента имени Н.П. Момотенка, аспирант. Основное направление исследований: технологии и технические средства производства биотоплива. E-mail: dvornykevgen@ gmail.com
Production from Safflower Straw Using Sodium Carbonate Pretreatment. Energy \& Fuels. 2016. Vol. 30, Iss. 12. P. 10592-10601. doi: 10.1021/acs.energyfuels.6b02468.

[25] Dehghani, M., Karimi, K., Sadeghi, M. Pretreatment of Rice Straw for the Improvement of Biogas Production. Energy \& Fuels. 2015. Vol. 29, Iss. 6. P. 3770-3775. doi: 10.1021/acs.energyfuels.5b00718.

[26] Polishchuk, V. M. Processes and equipment for biotechnological production of gaseous biofuels. Kyiv: NULES of Ukraine, 2015. 244 p.

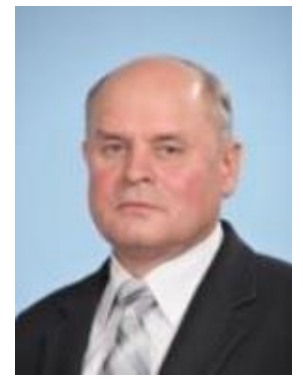

Шворов Сергей Андреевич. Национальный университет биоресурсов природопользования Украины, кафедра автоматики и робототехнических систем имени академика И.И. Мартыненка, доктор технических наук, профессор. Основная область исследований: создание робототехнических систем для сбора и переработки органического сырья.

E-mail: sosdok@nubip.edu.ua

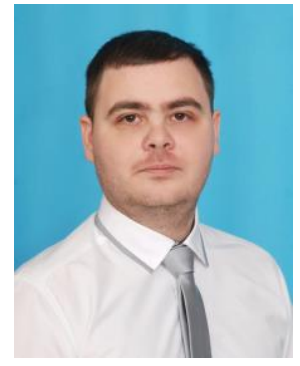

Давиденко Тарас Сергеевич.

Национальный университет биоресурсов

и природопользования

Украины, кафедра автоматики и робототехнических систем имени академика И.И. Мартыненка,

аспирант. Основная область исследований: автоматизированный контроль технологических процессов.

E-mail:

davidenkotaras009@gmail.com 